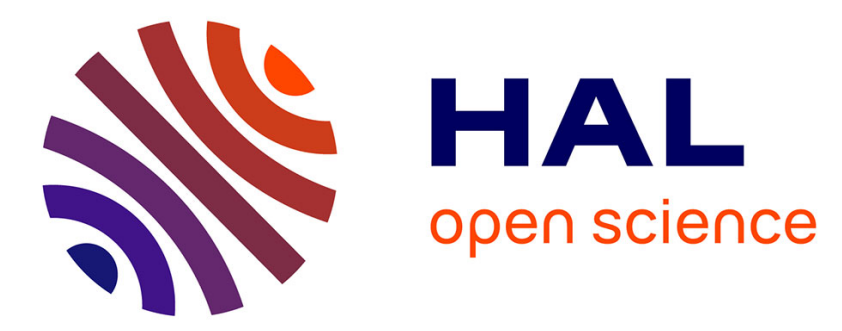

\title{
Response of a carbon-black filled SBR under large strain cyclic uniaxial tension
}

Mathias Brieu, Julie Diani, Christian Mignot, Christophe Moriceau

\section{To cite this version:}

Mathias Brieu, Julie Diani, Christian Mignot, Christophe Moriceau. Response of a carbon-black filled SBR under large strain cyclic uniaxial tension. International Journal of Fatigue, 2010, 32 (12), pp.1921-1927. 10.1016/j.ijfatigue.2010.06.002 . hal-02457837

\section{HAL Id: hal-02457837 https://hal.science/hal-02457837}

Submitted on 28 Jan 2020

HAL is a multi-disciplinary open access archive for the deposit and dissemination of scientific research documents, whether they are published or not. The documents may come from teaching and research institutions in France or abroad, or from public or private research centers.
L'archive ouverte pluridisciplinaire HAL, est destinée au dépôt et à la diffusion de documents scientifiques de niveau recherche, publiés ou non, émanant des établissements d'enseignement et de recherche français ou étrangers, des laboratoires publics ou privés. 


\title{
Response of a carbon-black filled SBR under large strain cyclic uniaxial tension
}

\author{
Mathias Brieu ${ }^{\mathrm{a}, *}$, Julie Diani ${ }^{\mathrm{b}}$, Christian $\operatorname{Mignot}^{\mathrm{c}}$, Christophe Moriceau $^{\mathrm{c}}$ \\ ${ }^{a}$ LML, Ecole Centrale de Lille, Bd Paul Langevin, 59650 Villeneuve d'Ascq, France \\ b PIMM, CNRS, Arts et Metiers ParisTech, 151 Bd de l'Hôpital, 75013 Paris, France \\ ${ }^{\mathrm{c}}$ Manufacture Française des pneumatiques Michelin, C.E.R.L. Ladoux, 63040 Clermont-ferrand, France
}

Keywords:

\begin{abstract}
A B S T R A C T
A carbon-black filled SBR was submitted to various uniaxial tension cyclic tests in order to study its cyclic softening. Stress-softening and stretch creep were monitored during stretch-control tests and ratcheting tests, respectively. The material softening induced by cyclic loadings appeared to depend on the maximum loading applied. The cyclic amplitude or equivalently the cyclic energy did not affect the material softening. The latter experimental result draws our attention since it contrasts with former results of the literature obtained on natural rubbers and butyl rubbers.
\end{abstract}

Cyclic stress/strain curve

Cyclic softening

Rubber

Stress amplitude

Strain-softening

\section{Introduction}

Rubbers are used in many industrial applications including tires, seals, shock and vibration absorbers,.... They are often submitted to cyclic loading conditions inducing first, a stress-softening and second, a fatigue failure recognizable by the appearance of a crack and its fatal propagation. Prediction of failure lifetime is crucial for design and maintenance of mechanical structures, and it is well known that the cyclic load history affects the material fatigue. While many studies focused on the failure lifetime (see [1] for a review), characterizing lifetime [2-4], observing the fracture surface $[5,6]$, proposing lifetime failure criteria [7-9], fewer discussed the stress-softening [10-13]. This paper studies the stress-softening of a carbon-black filled SBR under various cyclic uniaxial tension conditions.

During the first few cycles of cyclic loadings, filled and crystallizing rubber-like materials undergo a substantial stress-softening, which is known as the Mullins effect [14,15]. The stress-softening occurring after these first few cycles evolves slowly, and therefore is often neglected when modelling the mechanical behaviour of these materials. Nonetheless, the latter can no longer be neglected when dealing with fatigue. Study on the fatigue of filled rubber-like materials [10-12] present an obvious dependence of the material softening to the maximum stretch level ever submitted, but the cycle amplitude effect remain questionable. In order to

\footnotetext{
* Corresponding author. Tel.: +33 320335375 .

E-mail address: mathias.brieu@ec-lille.fr (M. Brieu).
}

avoid crystallization interference, we worked on a carbon-black filled SBR. We ran tests at a strain rate of $10^{-1} \mathrm{~s}^{-1}$, which is low according fatigue standard in order to reduce a possible viscosity effect. We applied various loading history in order to decide on the effect of the cycle amplitude, the overload history and the underload history, on the stress-softening and stretch creep of the material.

\section{Experiments}

Filled styrene butadiene rubbers are often used for tire applications. In this study, experiments were carried out on a carbonblack filled SBR supplied by Michelin. The material formulation is given in Table 1 . Normalized dumbbell shape specimens [16] (25 mm long and $4 \mathrm{~mm}$ wide) were punched into plates of $2 \mathrm{~mm}$ of thickness. Loads were measured by a $1 \mathrm{kN}$ load cell. All cyclic tests were conducted, at room temperature, on an Instron 5802 uniaxial tension machine operated in displacement control mode at a constant crosshead speed of $500 \mathrm{~mm} \mathrm{~min}^{-1}$. Local strains were measured by video extensometry. Below, the various loading conditions that were applied are listed:

- Test A1: Stretch-control cycles with a constant maximum stretch $\lambda_{\max }$ and a constant minimum load of $F=0$. The value of $F=0 \mathrm{~N}$ was chosen in order to avoid compressive loading resulting into the buckling of the specimen due to its low thickness. The maximum stretch $\lambda_{\max }$ was chosen between 2.0 and 4.0 which corresponds to a strain between $100 \%$ and $300 \%$. 
Table 1

Compounding formulation of the SBR

\begin{tabular}{lc}
\hline Ingredient & $\mathrm{Phr}$ \\
\hline SBR gum & 100 \\
N347 (carbon-black) & 30 \\
6PPD (antioxidant) & 1 \\
Stearic acid & 2 \\
ZnO & 5 \\
CBS & 1.2 \\
Sulfur & 1.2 \\
\hline
\end{tabular}

- Test A2: Stretch-control cycles with a constant maximum stretch $\lambda_{\max }$ and a constant minimum stretch chosen between $\frac{1}{4} \lambda_{\max }$ and $\frac{3}{4} \lambda_{\max }$.

- Test A3: Stretch-control cycles with a constant maximum stretch $\lambda_{\max }$ and a constant minimum load of $F=0 \mathrm{~N}$ disrupted by 1000 consecutive cycles at a lower maximum stretch.

- Test A4: Stretch-control cycles with five cycles of a maximum stretch $\lambda_{\max }$ and a minimum load of $F=0 \mathrm{~N}$, followed by cycles of a lower amplitude from a minimum load of $F=0 \mathrm{~N}$ to a constant maximum stretch between $\frac{1}{4} \lambda_{\max }$ and $\frac{3}{4} \lambda_{\max }$.

- Test B1: Stress-control cycles with a maximum engineering stress $\tau_{\max }$ and a minimum force $F=0 \mathrm{~N}$. The maximum stress considered here was $\tau_{\max }=6.2 \mathrm{MPa}$, which corresponds to $250 \%$ of strain during the first cycle.

- Test B2: Stress-control cycles with a maximum engineering stress $\tau_{\max }$ and a stress amplitude from $\frac{1}{4} \tau_{\max }$ to $\tau_{\max }$.

- Test B3: Stress-control cycles with five cycles of a maximum engineering stress $\tau_{\max }$ and a minimum load of $F=0 \mathrm{~N}$, followed by cycles of a lower amplitude from a minimum load $F=0 \mathrm{~N}$ to a constant maximum engineering stress chosen between $\frac{1}{4} \tau_{\max }$ and $\frac{3}{4} \tau_{\max }$

Tests A1 and B1 will provide with experimental evidences of the material softening during cyclic loading conditions, and of the effect of the level of the peak loading. The effect of the amplitude of the cycles will be studied with tests A2 and B2. Test A3 will show whether lower stretch cycles may affect the stress-softening at higher stretches. Finally, the possible effect of an overloading will be shown by tests A4 and B3.

All specimens were loaded from 500 to 2000 cycles, results are presented in the next section.

\section{Results}

\subsection{Strain-control tests}

Fig. 1 illustrates the stress-strain response of a filled rubber submitted to a stretch-control cyclic uniaxial tension (Test A1). During the first cycle, the material exhibits a Mullins effect characterized by a large hysteresis, a large stress-softening, a subsequent decrease of the tangent modulus and a resulting permanent set. After the first few cycles, the Mullins effect stabilizes and will not affect the material until it is submitted to a higher stretch [15]. During the following cycles, a slow stress-softening along with a very slow evolution of the tangent modulus is observed. We characterized the stress-softening, which is the decrease of the peak stress vs. the number of cycles, by the ratio:

$R=\frac{\tau\left(\lambda_{\max }, N\right)}{\tau\left(\lambda_{\max }, 1\right)}$

where $N$ is the cycle number and $\tau$ is the engineering stress. We plotted in Fig. 2, the stress-softening ratio $R$ according to $\lambda_{\max }$ and to the number of cycles. One can notice that the cyclic stress-softening is increasing with the maximum stretch. We noticed that after 40 cycles, the stress-softening decreases linearly with $\ln (N)$. A similar result is reported in [11,17], beyond 100 cycles. Also, $\mid d$ $R / d \ln (N) \mid$ is increasing with the maximum stretch and therefore the softening rate increases with the increase of the peak stretch.

The change of the permanent set was also monitored while the material softens. Fig. 3 shows the stretch at $F=0 \mathrm{~N}$ according to the number of cycles. As reported in Mullins effect studies, the permanent set at the first cycle increases with the increase of the maximum stretch. During the following cycles, the permanent set evolves slowly. Its change is dependent of the maximum stretch applied.

In order to decide on the influence of the stretch amplitude on the material softening, we carried out four tests with identical maximum stretch and various stretch amplitudes defined by the minimum stretch, $\frac{1}{4} \lambda_{\max }, \frac{1}{2} \lambda_{\max }$ and $\frac{3}{4} \lambda_{\max }$, or the minimum force $F=0 \mathrm{~N}$ (Test A2). We reported in Fig. 4, the stress-softening ratio $R$ (1) according to the number of cycles for these tests, the maximum strain being set to $250 \%$. In this figure, the material softening is similar for all stretch amplitudes.

Dual tests in stress-control mode were conducted and are presented in the next section.

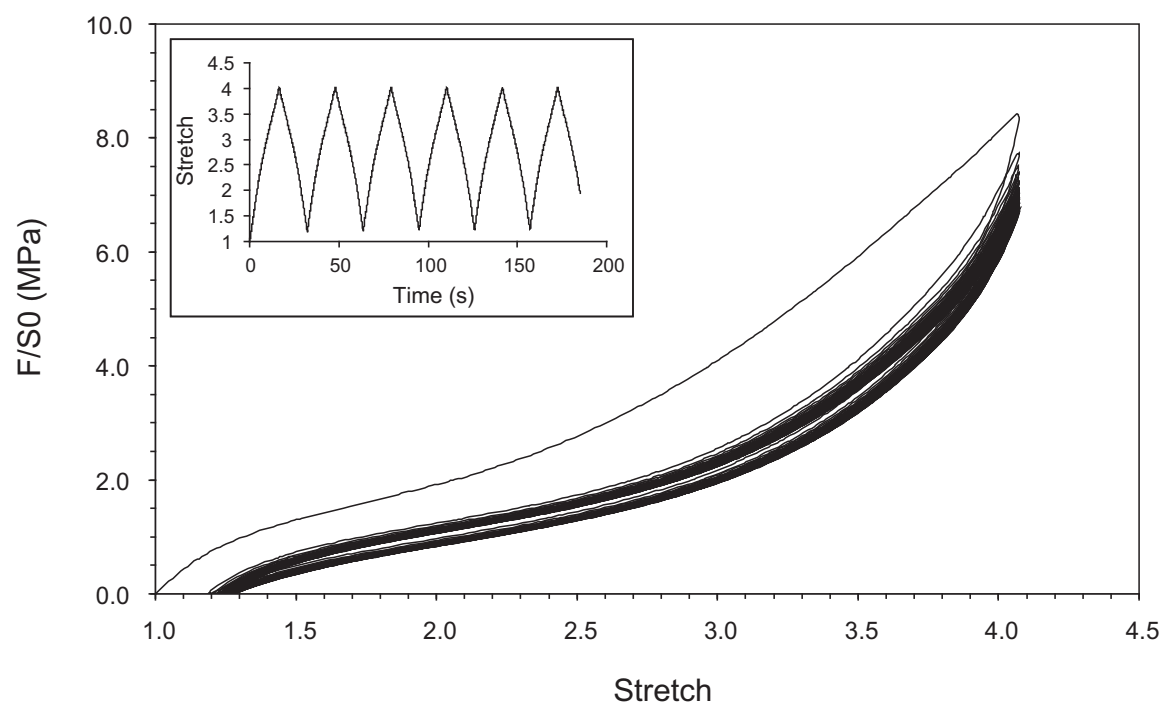

Fig. 1. Stress-strain response of a filled SBR submitted to a cyclic uniaxial tension test at constant maximum stretch (Test A1). 


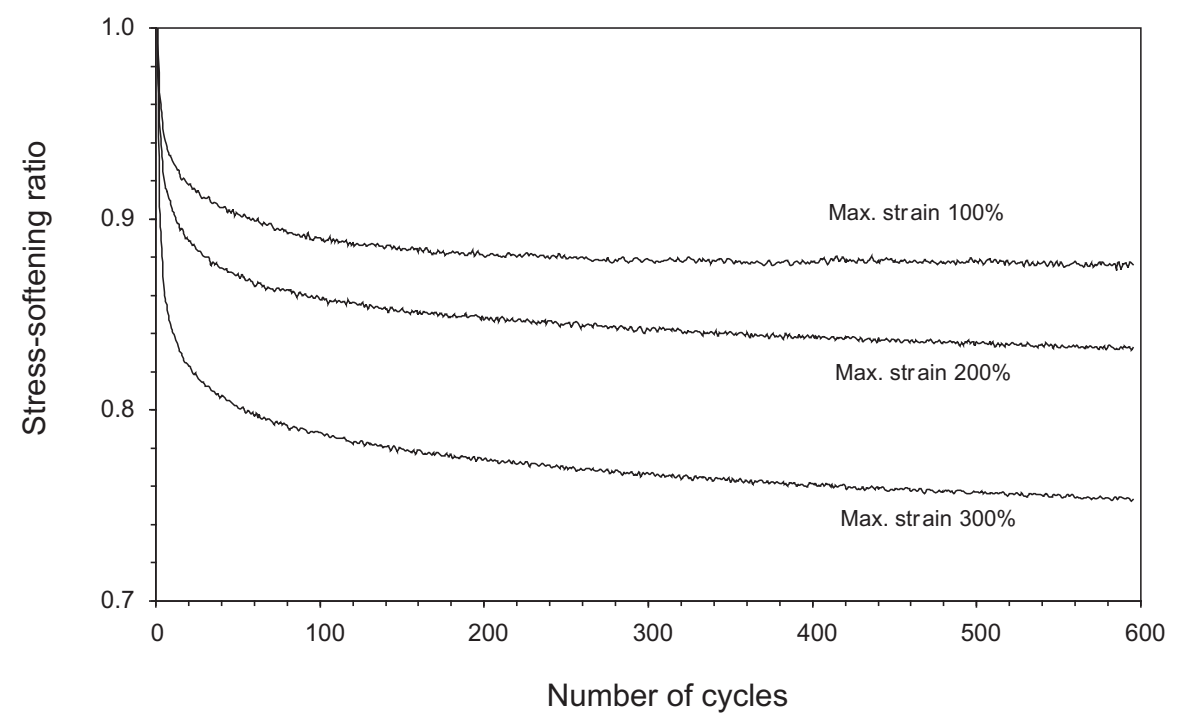

Fig. 2. Stress-softening ratio vs. the number of cycles during cyclic uniaxial tension tests at constant peak stretch (Test A1).

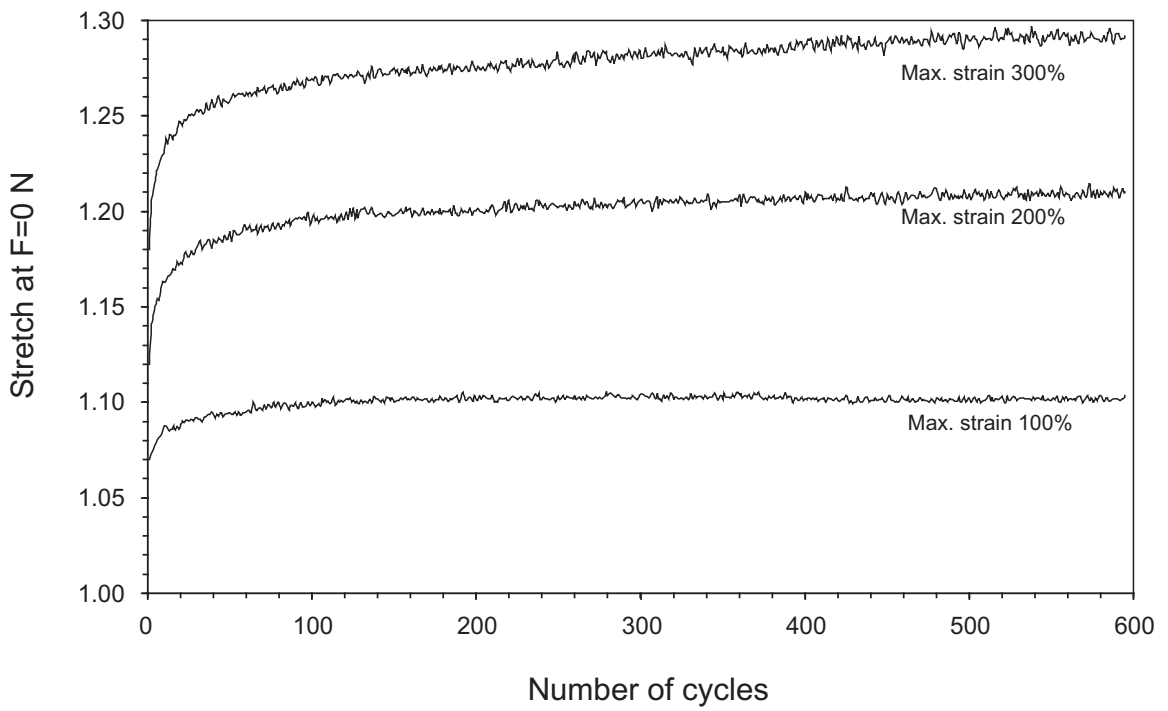

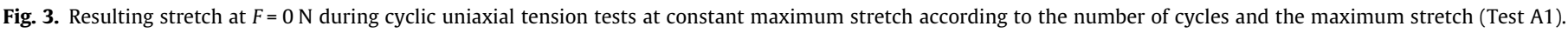

\subsection{Ratcheting tests}

Fig. 5 shows the stress-stretch behaviour of the material submitted to a cyclic uniaxial tension with a constant maximum stress peak and a constant null minimum stress (Test B1). The material evidences a large change of maximum stretch at the first cycle, associated to the Mullins effect, then the maximum stretch evolves slowly. In order to compare, the stretch creep at the maximum stress for various levels of stress, we introduce the ratcheting stretch ratio defined by:

$S=\frac{\lambda_{\max }\left(\tau_{\max }, N\right)}{\lambda_{\max }\left(\tau_{\max }, 1\right)}$

Values of $S$ are plotted vs. the number of cycles for two stress levels in Fig. 6. As expected the ratcheting stretch increases with the increase of the peak stress. We noted that beyond forty cycles, $S$ evolves linearly with respect to $\ln (N)$. Also, like for $R$, $|d S / d \ln (N)|$ increases with the stress peak.

Like in stretch-control mode, we ran several tests with an identical peak stress but various cycle amplitudes to test the cycle amplitude effect (Test B2). Three tests were run at a maximum engineering stress of $2.6 \mathrm{MPa}$ and stress amplitude of $\tau_{\max }, \frac{1}{4} \tau_{\max }$ and $\frac{1}{2} \tau_{\max }$. We reported the value of $S$ vs. the number of cycles for the three tests in Fig. 7. Clearly, the ratcheting stretch is not affected by the cycle stress amplitude.

Next, we studied the possible effect of pre-loadings on the material softening.

\subsection{Effect of a pre-loading}

First, we submitted one sample to a cyclic loading at a constant maximum strain of $250 \%$, and second, we submitted another sample to five cycles at $250 \%$ of strain followed by 1000 cycles at $100 \%$ of strain and then by 500 cycles at $250 \%$ of strain (Test A3). For both tests, we calculated the stress-softening ratio $R$, defined in (1), at $250 \%$ and plotted it in terms of the cycle number reaching this level of stretch only. Fig. 8 shows how $R$ evolves in both cases. Plots are similar for both tests and evidence that the relatively large number of cycles at a lower stretch did not significantly affect the material softening at $250 \%$. 


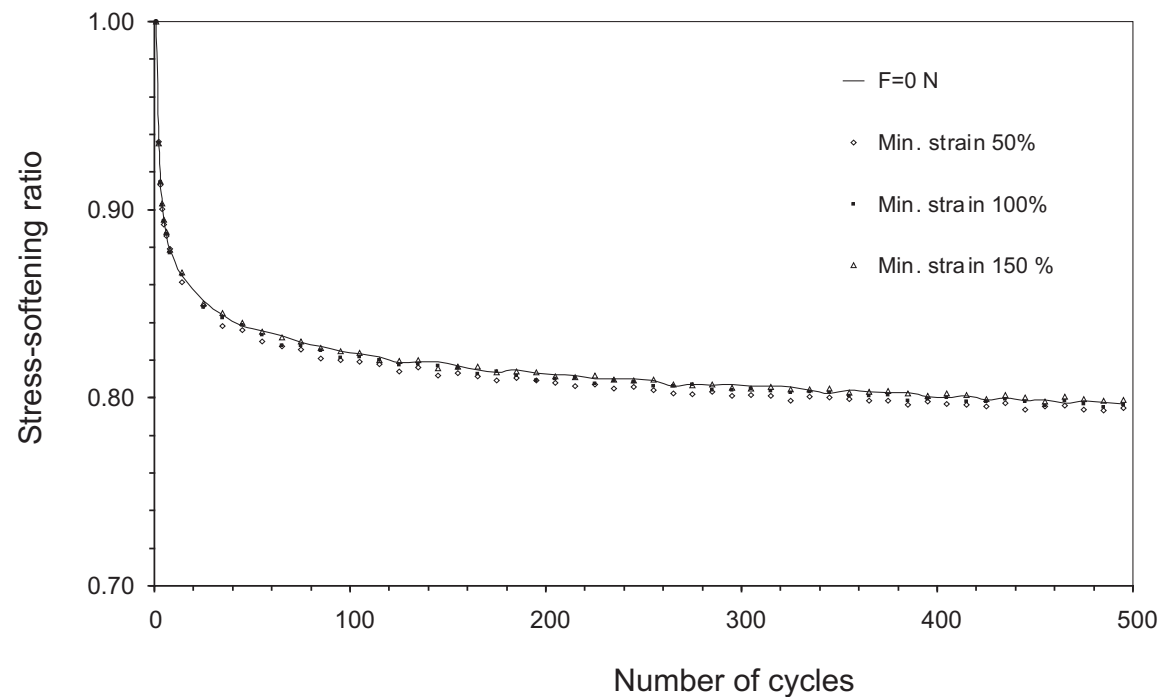

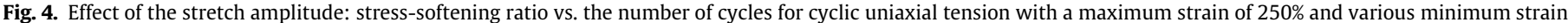
(Test A2).

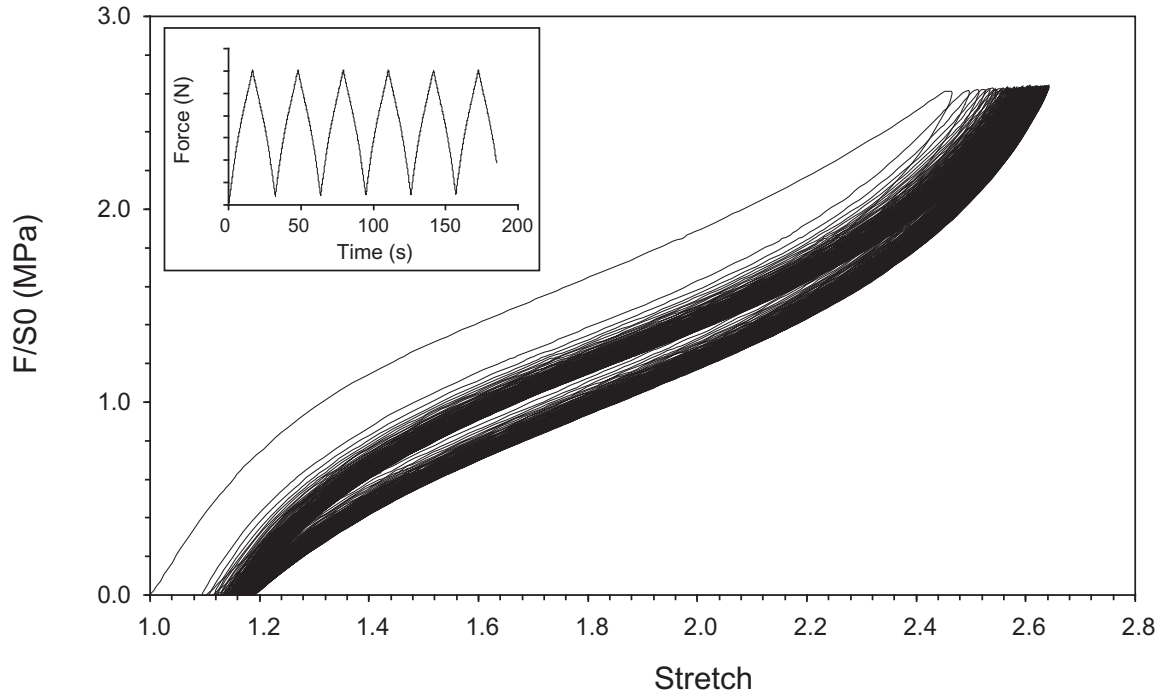

Fig. 5. Stress-strain response of a filled SBR submitted to a cyclic uniaxial tension test at constant maximum stress (Test B1).

In order to study the effect of an overloading, cyclic tests were preceded by five cycles at a higher stretch (Test A4). Fig. 9 illustrates the engineering stress measured at the peak stretch vs. the number of cycles, for cyclic tension tests at 225\%, $175 \%$ and $100 \%$ maximum of strain preceded by five cycles at $250 \%$. After a previous overloading, one notes that the stress at lower stretch remains constant over the cycles. Also, by comparing Figs. 1 and 9, one notices that the overload induced a large reduction of the stress. When the pre-stretch is substantial compared to the cyclic peak stretch, one observes during the first few cycles an increase of the peak stress. In Fig. 9, such a behaviour appears for the cycles at $100 \%$. This "stiffening" effect is the consequence of the material viscosity. A similar results was reported in [11] for a subsequent overload. It is worth mentioning here that the overload does not need to be significantly higher. Fig. 9 shows a frozen stress-softening for cycles at $225 \%$ strain, while the overload reached a strain of $250 \%$. Similar tests were carried out with a single cycle of overloading, it appeared that one cycle was not sufficient to freeze the stress-softening.
Last, we carried out stress-control tests with an overload (Test B3). We submitted some samples to five cycles of overload at 4.6 MPa and monitored the stretch ratcheting during the following cycles reaching a peak of $2.3 \mathrm{MPa}$ and $3.45 \mathrm{MPa}$, respectively. Fig. 10 shows a freezing effect of the overload on the ratcheting effect, which corroborates the result obtained with the stretch-control tests.

\section{Discussion}

The first evidence provided by the results presented in the section above, is that the stress-softening (resp. stretch creep) occurring during cyclic loadings depends on the maximum stretch (resp. stress) ever submitted to the material. Figs. 2 and 6 show that when no previous loading was applied, the stress-softening (resp. stretch creep) during cyclic loadings is strongly dependent of the stretch peak (resp. stress peak). Similar results were obtained by McKenna and Zapas [10] or Yu et al. [12]. McKenna and Zapas 


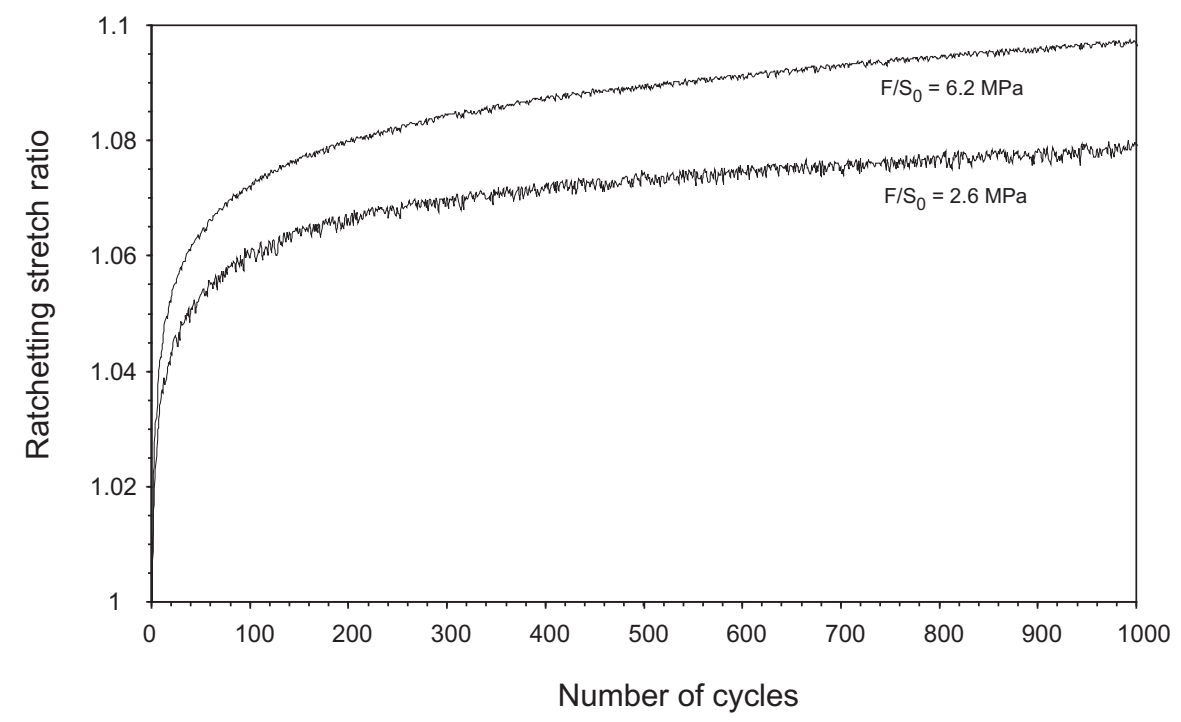

Fig. 6. Stretch creep vs. the number of cycles during cyclic uniaxial tension ratcheting tests (Test B1).

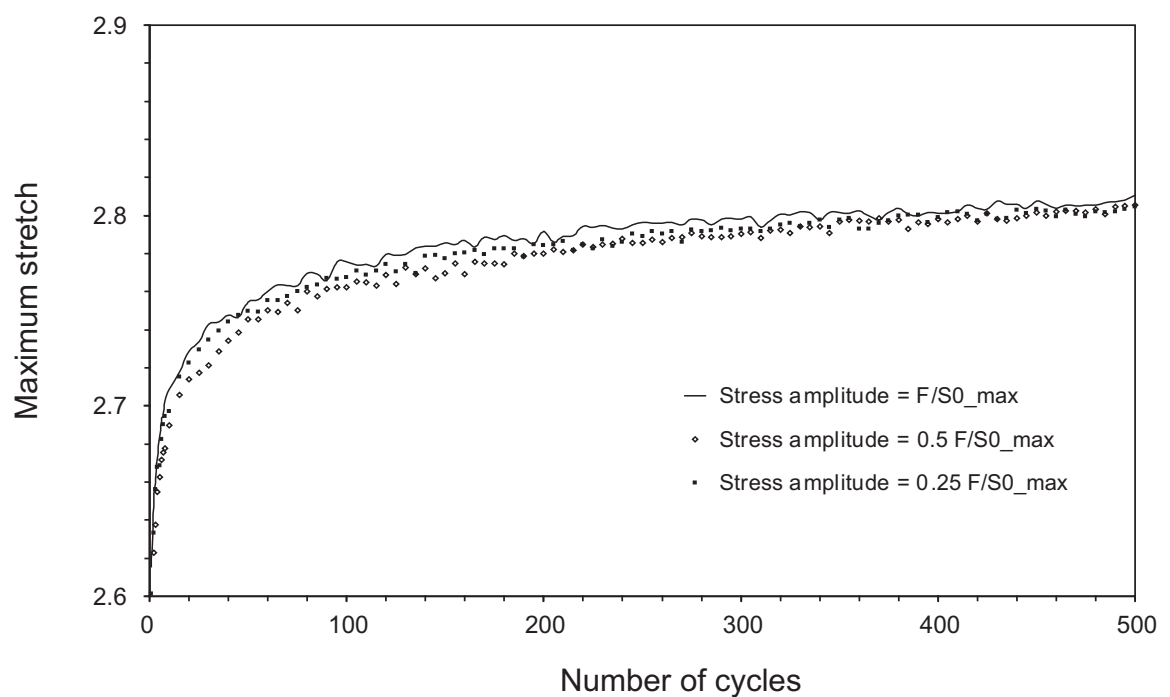

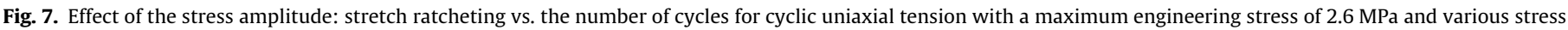
amplitudes (Test B2).

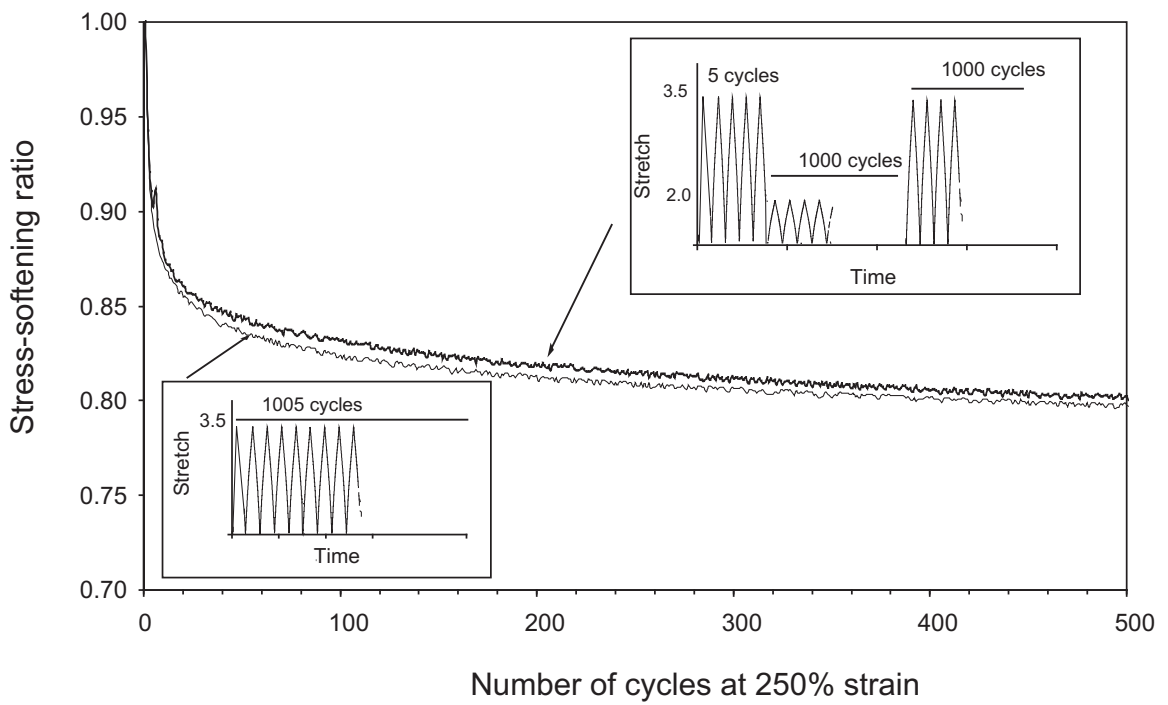

Fig. 8. Effect of the loading history: stress-softening at $250 \%$ strain vs. the number of cycles reaching this stretch level (Test $A 3$ ). 


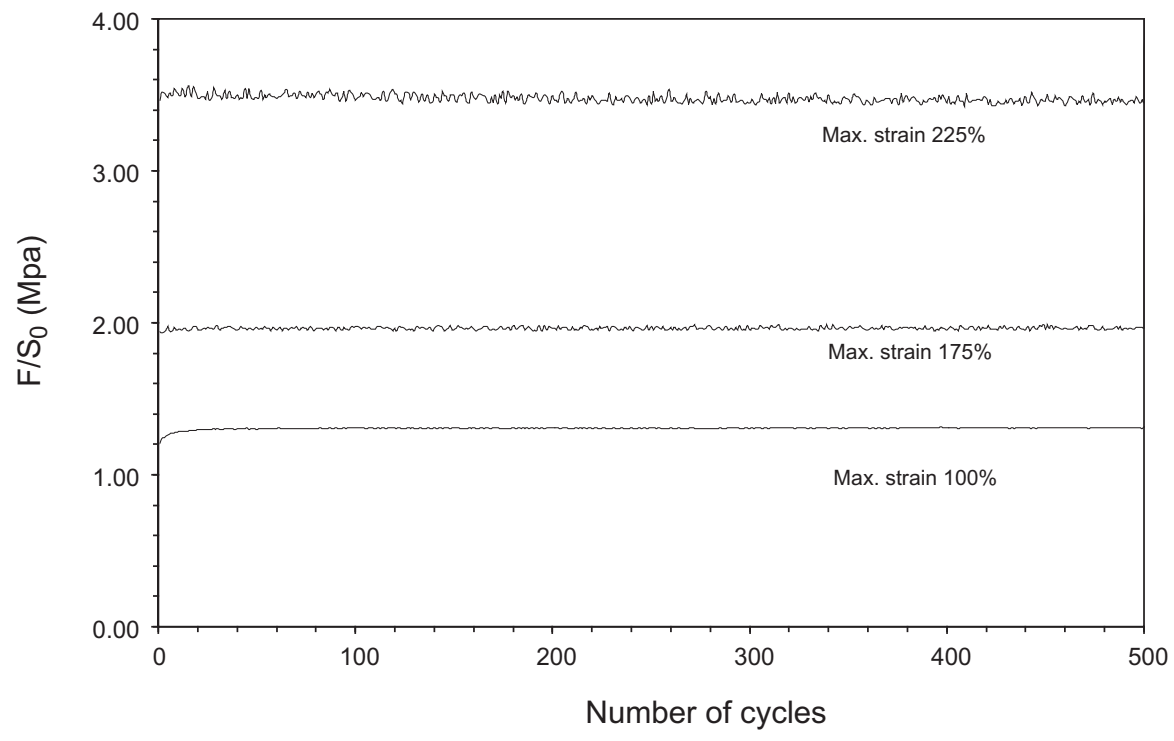

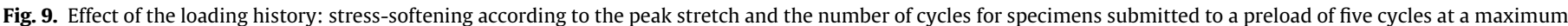
strain of $250 \%$ (Test A4).

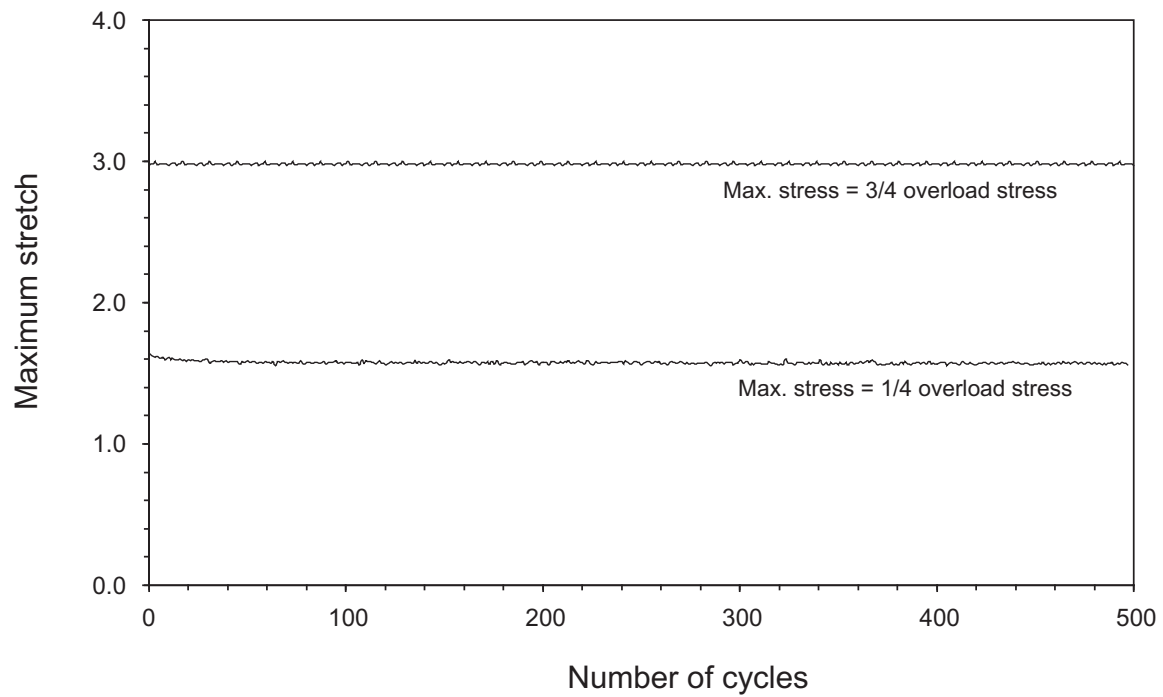

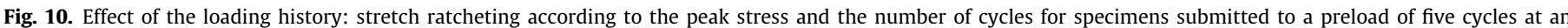
engineering stress of $4.6 \mathrm{MPa}$ (Test B3).

[10] conducted uniaxial tension cyclic tests on filled butyl rubber for a moderate number of cycles (100) with constant maximum stretch on one side and with constant maximum stress on the other side. They observed that the stress-softening and the stretch creep depend on the maximum stretch and the maximum stress, respectively. Yu et al. [12] conducted ratcheting tests of 50-150 cycles, on a filled natural rubber with various maximum stresses and cycle amplitudes and also concluded that the maximum stress level affects the stretch creep under uniaxial cyclic loading conditions. When an overloading is applied prior to the cyclic loading, Figs. 9 and 10 showed that the material softening was frozen by the overloading. Mars and Fatemi [11] explored the cyclic behaviour of a filled natural rubber under multiaxial stress conditions. They also observed that the stress softening could completely disappear by prescribing an initial substantial overload during 10 cycles. They mentioned that in such a condition, the stress corresponding to the applied stretch is lower than the stress measured without previous overload, which is consistent with our results. Yu et al. [12] also observed that the stretch creep could disappear when preceded by an overload. One of the interesting aspects of Fig. 9 is that it reveals that the overload does not need to be substantially higher than the cyclic maximum loading, actually it can be very close. This might be the experimental proof that the Mullins effect taking place at the first few cycles and the stresssoftening taking place during the following cycles have the same physical origin, since by imposing a larger Mullins effect, the stress-softening is stabilized.

The second crucial information provided by our experiments, is found in Figs. 4 and 7. The cycle amplitude does not affect the stress-softening or equivalently the stretch creep during cyclic loadings. This result differs from previous results reported in the literature [10,12]. In the case of Yu et al. [12] work, a cautious look at the data plotted in the latter contribution reveals an effect of the stress amplitude parameter for the higher stress level only. For 
moderate stress (up to $2.5 \mathrm{MPa}$ ), their experimental results show that stress-amplitude does not affect the ratcheting. Moreover, their material is a crystallizing rubber, and it is well known that crystallization can improve the fatigue life under non-relaxing uniaxial tension loading [18] since reducing the stretch amplitude of the cycles induces a partial melting of the crystallites produced by the tensile load. Therefore, a permanent crystallization is set in the material, which obviously may affect its softening. In the case of SBR, the gum cannot crystallize and we observe that the stretch amplitude is not a factor in the cyclic softening. A consequence of this result is that the energy cannot be a parameter of the material softening even though it seems to be a parameter of fatigue $[2,11]$. In the case of the results obtained on a butyl rubber [10], even though crystallization may happen under high strain loadings, it is unlikely that the reported dependence of the softening to the cyclic amplitude is due to crystallization. For the moment, the only parameter that may explain the difference between our results and those of McKenna and Zapas [10], is the strain rate. Until now, this question remains open.

\section{Conclusion}

This work explored the stress-softening of a filled SBR rubber submitted to uniaxial tension cyclic tests. Stretch-control and stress-control tests were conducted in order to assess the parameters controlling the stress-softening and the stretch creep, respectively. The experimental results provide a complete characterization of the softening of a non-crystallizing filled rubber submitted to moderate strain rate cyclic uniaxial tension.

On one hand, the material softening and the permanent set induced by cyclic loadings appeared to depend on the maximum loading. Experimental data showed that the softening increased with the peak of the cyclic tests and that beyond forty cycles, the stress-softening evolved linearly with $\ln (N)$. Also, by exposing the material to overloads, we observed that even when the overload was not substantial, the softening froze. On the other hand, the material softening was not affected by the cyclic amplitudes, which shows that the cyclic amplitude or equivalently the cyclic energy cannot be a parameter controlling the material softening. Other data confirmed the latter result, the loading history happening at lower stretches did not affect the stress-softening. These experimental evidences contrast with former results of the literature obtained on natural rubbers and butyl rubbers.

\section{References}

[1] Mars W, Fatemi A. A literature survey on fatigue analysis approaches for rubber. Int J Fatigue 2002;24:949-61.

[2] Abraham F, Alshuth T, Jerrams S. The effect of minimum stress and stress amplitude on the fatigue life of non strain cyrstallising elastomers. Mater Des 2005;26:239-45.

[3] Kim J, Jeong H. A study on the material properties and fatigue life of natural rubber with different carbon blacks. Int J Fatigue 2005;27:263-72.

[4] Mars W, Fatemi A. Multiaxial stress effects on fatigue behavior of filled natural rubber. Int J Fatigue 2006;28:521-9.

[5] Goldberg A, Lesuer DR. Fracture morphologies of carbon-black-loaded SBR subjected to low-cycle high-stress fatigue. Rubber Chem Technol 1989;62:272-87.

[6] Cam JL, Huneau B, Verron E. Description of fatigue damage in carbon black filled natural rubber. Fatigue Fract Eng Mater Struct 2008;31:1031-8.

[7] Saintier N, Cailletaud G, Piques R. Multiaxial fatigue life prediction for a natural rubber. Int J Fatigue 2006;28:530-9.

[8] Harbour R, Fatemi A, Mars W. Fatigue life analysis and predictions for nr and SBR under variable amplitude and multiaxial loading conditions. Int J Fatigue 2008;30:1231-47.

[9] Verron E, Andriyana A. Definition of a new predictor for multiaxial fatigue crack nucleation in rubber. J Mech Phys Solids 2008;56:417-43.

[10] McKenna G, Zapas L. Response of carbon black filled butyl rubber to cyclic loading. Rubber Chem Technol 1981;54:718-33.

[11] Mars W, Fatemi A. Observations of the constitutive response and characterization of filled natural rubber under monotonic and cyclic multiaxial stress states. J Eng Mater Technol 2004;126:19-28.

[12] Yu W, Chen X, Wang Y, Yan L, Bai N. Uniaxial ratchetting behavior of vulcanized natural rubber. Polym Eng Sci 2008;48:191-7.

[13] Wang Y, Chen X, Yu W, Yan L. Experimental study on multiaxial ratcheting behavior of vulcanized natural rubber. Polym Eng Sci 2009;49:507-13.

[14] Mullins L. Softening of rubber by deformation. Rubber Chem Technol 1969;42:339-62.

[15] Diani J, Fayolle B, Gilormini P. A review on the Mullins effect. Eur Polym J 2009;45:601-12.

[16] Brown RP. Physical testing of rubber, 3rd ed. Chapman and Hall.

[17] Gentot L, Brieu M, Mesmacque G. Modelling of stress-softening for elastomeric materials. Rubber Chem Technol 2004;77:758-74.

[18] Cadwell S, Merrill R, Sloman C, Yost F. Dynamic fatigue life of rubber. Ind Eng Chem 1940;12:19-23. 